\title{
Smaller Copper Oxide Nanoparticles have More Biological Effects Versus Breast Cancer and Nosocomial Infections Bacteria
}

\author{
Ardeshir Abbasi ${ }^{1,2}$, Khodayar Ghorban ${ }^{1,2}$, Farshad Nojoomi ${ }^{3}$, Maryam \\ Dadmanesh $^{1,4 *}$
}

\begin{abstract}
Background and Objectives: Despite promising successes in developing new drugs and pharmaceutical biotechnology, infectious diseases and cancer are still the principal causes of mortality and morbidity globally. Therefore, finding effective ways to deal with these pathogens and cancers is critical. Metal nanoparticles are one of the new strategies to combat bacteria and cancers. Methods: We examined the antimicrobial activity of 30 and $60 \mathrm{~nm}$ copper oxide nanoparticles (CuO-NPs) against Acinetobacter baumannii and Staphylococcus epidermidis bacteria responsible for nosocomial infections in standard and clinical strains and anti-cancer activity against $4 \mathrm{~T} 1$ cell line as malignancy breast cancer cells. Synthesis of CuO-NPs was performed by a one-step reduction method and confirmed by DLS and TEM microscopy at 30 and $60 \mathrm{~nm}$ sizes. The antibacterial and anti-cancer activities of the nanoparticles were then investigated against the aforementioned bacteria and breast cancer. Results: Using disk, well, MIC, MBC methods, and viability/bacterial growth assay, $30 \mathrm{~nm} \mathrm{CuO} \mathrm{NPs} \mathrm{were} \mathrm{found} \mathrm{to} \mathrm{have} \mathrm{more} \mathrm{antibacterial} \mathrm{activity} \mathrm{on} \mathrm{standard} \mathrm{and}$ clinical strains than $60 \mathrm{~nm} \mathrm{CuO} \mathrm{NPs.} \mathrm{On} \mathrm{the} \mathrm{other} \mathrm{hand,} \mathrm{using} \mathrm{MTT,} \mathrm{apoptosis,} \mathrm{and} \mathrm{gene} \mathrm{expression} \mathrm{method,} 30 \mathrm{~nm}$ nanoparticles were found to have more anti-cancer potential than $60 \mathrm{~nm} \mathrm{CuO} \mathrm{NPs.} \mathrm{Conclusions:} \mathrm{Our} \mathrm{findings} \mathrm{implicate}$ $\mathrm{CuO}-\mathrm{NPs}$ to possess antimicrobial and anti-cancer effects and more significant potential in smaller sizes, suggesting their pharmaceutical and biomedical capacity.
\end{abstract}

Keywords: Copper oxide nanoparticle- acinetobacter baumannii-Staphylococcus epidermidis- nosocomial infections

Asian Pac J Cancer Prev, 22 (3), 893-902

\section{Introduction}

Nosocomial infections (NIs) are among the most critical problems affecting all hospitals worldwide and one of the health issues among all societies. Controlling the spread of these infections remains a significant challenge, especially in hospitals. Moreover, cancer is one of the biggest medical concerns. Breast cancer is the second leading cause of death among women all around the world. NIs and cancer lead to increased morbidity, mortality, cost, and hospitalization, as well as inflicting staff and economic pressure to the health centers (Motbainor et al., 2020). The rapid emergence of antibiotic-resistant bacteria has affected the efficacy of infectious disease treatment and the health of millions of patients worldwide (Kajihara et al., 2020). Multi-drug resistance (MDR) has been recently reported to be responsible for 700,000 annual deaths and is predicted to reach 10 million deaths in 2050 , providing that new antibacterial agents are not being developed
(Maddila et al., 2020). The two bacteria responsible for the majority of nosocomial infections are Staphylococcus epidermidis (S. epidermidis) and Acinetobacter baumannii (A. baumannii (Staphylococci are critical pathogens for humans, which cause a wide range of dangerous systemic diseases (skin infections and opportunistic infections) (Da et al., 2017). Staphylococcus epidermidis (S. epidermidis) (coagulase-negative, gram-positive cocci) is one of the most important opportunistic pathogens in medical devices; therefore, it is mainly associated with medical-device infections. S. epidermidis is one of the common-colonized bacteria in human skin (Amaro et al., 2019). Acinetobacter baumannii (A. baumannii) is an aerobic and polymorphic gram-negative bacterium, which is highly resistant to common antibiotics because it is isolated from the hospital gut (Grandesso et al., 2014; Atik et al., 2018). Therefore, these bacteria can be considered to impose future threats and cause hospital infections. Importantly, instant actions to deal with these pathogens

${ }^{1}$ Infectious Diseases Research Center, Aja University of Medical Sciences, Tehran, Iran. ${ }^{2}$ Department of Immunology, School of Medicine, Aja University of Medical Sciences, Tehran, Iran. ${ }^{3}$ Department of Microbiology, School of Medicine, Aja University of Medical Sciences, Tehran, Iran. ${ }^{4}$ Department of Infectious Diseases, School of Medicine, Aja University of Medical Sciences, Tehran, Iran.*For Correspondence:dr.dadmanesh@gmail.com 
is one of the global health priorities. Breast cancer is still important similar to 2019, that was reported with an outbreak of 268,600 new cases in the United States. 4T1 breast carcinoma is a triple-negative tumor cell line that is highly invasive, metastatic, and tumorigenic (Abbaset al., 2020; Abbasi et al., 2021). Furthermore, the number of cancer patients is increasing every day. Therefore, finding effective ways to tackle these pathogens and cancers is critical.

Nanoscale materials have long been the focus of researchers and materials scientists. The reduction in particle size from micro to nano has led to the emergence of specific properties such as hardness, high electrical conductivity, increased surface-to-volume ratio, high reactivity, and altered biological activity (Ilinskaya et al., 2019). Such properties enable the particles to interact with microbes, bacterial membranes, and cancerous cells more meritoriously. Hence, they gradually release metal ions along the membrane (Yang et al., 2012). The toxic activity of metal NPs, including gold, copper, zinc, and titanium, has been of great interest for treatment options (Babaei et al., 2017; Kukia et al., 2018; Kukia et al., 2018). More attention has been focused on silver and copper nanoparticles that have intrinsic antibacterial, anti-cancer, and antioxidant properties because of their comfortable and rapid use, availability, low-concentration toxicity, and lack of environmental hazards (Ali et al., 2020). CuO-NPs, with different morphological structures, may have multifunction biology activities such as antibacterial and anti-cancer roles, which are produced using various synthetic pathways such as precipitation (Mayekar et al., 2014; Kukia et al., 2018), electrochemical synthesis (Katwal et al., 2015), thermal decomposition (Shahsavani et al., 2016), sono-chemical synthesis (Silva et al., 2019), heat treatment approach (Baqer et al., 2018), nonionic water-in-oil micro-emulsions (Dodoo-Arhin et al., 2012), sol-gel synthesis (Dörner et al., 2019) and Laser Ablation in Open Air (Fernández-Arias et al., 2020). Previous studies have also shown that the effect of nanoparticles is size-dependent (Albanese et al., 2012). Nevertheless, studies aimed at assessing the professional performance of NPs, adverse effects, biosecurity, and toxicology are still scarce. Therefore, in this study, a one-step reduction method was used to prepare an aqueous colloidal aqueous solution without toxicants to produce a strong disinfectant at multi-biological effects. Moreover, we compared the biological effect of $\mathrm{CuO}-\mathrm{NPs}$ at two different sizes of 30 and $60 \mathrm{~nm}$ on two A. baumannii and S. epidermidis bacteria, representing gram-negative and positive bacteria respectively, responsible for nosocomial infections in standard and clinical strains and 4T1 breast cancer cell line as representative of malignant cells to an evaluation of their pharmaceutical and biomedical properties (see Figure 1).

\section{Materials and Methods}

\section{Materials and strains of the bacteria investigated}

This fundamental and applied study was accompanied under the supervision of the Ethics Committee of Army Medical University. In this study, standard strains were prepared of $A$. baumannii (ATCC BAA-747), and S. epidermidis (ATCC 49461) from Iranian Biological Research Center, while clinical strains were obtained from Army Hospital. They were selected as representative of the Gram-positive ( $S$. epidermidis) and negative (A. baumannii) bacteria responsible for antibiotic resistance and hospital infections. Culture media, nutrient broth, Mueller Hinton Agar, BHI, Peptone Water, brain agar, and Tryptic Soy Broth were used. All culture media were purchased from Merck Company (Merck-Germany).

Investigation antibiotic-resistant clinical strains of A. baumannii and S. epidermidis bacteria by antibiogram test

To performed this test, each clinical bacteria strain was cultured distinctly using a germ-free swab on Mueller Hinton agar. Antibiotic discs, such as Gentamicin, Cefpodoxime, Ciprofloxacin, Cefdinir, Trimethoprim-sulfamethoxazole, Novobiocin, and Erythromycin, were used against $S$. epidermidis and Piperacillin, Imipenem, Gentamicin, Ciprofloxacin, Cefotaxime, and Ampicillin-sulbactam were used against A. baumannii. Then the cultured plates had been incubated 24 hours at $37^{\circ} \mathrm{C}$. After incubation, the diameter of the inhibition-zone shaped around the disks was measured using a caliper and determined in the mm unit.

\section{Synthesis and characterization of $\mathrm{CuO}-\mathrm{NPS}$}

A one-step reduction method was used to prepare an aqueous copper colloid solution, described by Han. et al, (2011) (Han, Song et al. 2010). For this purpose, firstly, $0.25 \mathrm{gr}$ of copper sulfate $\left(\mathrm{CuSO}_{4} .5 \mathrm{H}_{2} \mathrm{O}\right)$ was dissolved in $100 \mathrm{ml}$ distilled water. After that, $5 \mathrm{gr}$ of Polyvinylpyrrolidone (PVP-K30) (Merck-Germany) was dissolved in the equipped aqueous solution. Then, 0.25 gr of $\mathrm{NaBH}_{4}$ was used to reduce the copper oxide under stirring situations and at the controlled temperature $\left(25^{\circ} \mathrm{C}\right)$ and atmosphere $(1 \mathrm{~atm})$. Accordingly, the color of the copper sulfate solution altered to green, and the color of the solution turned in brown after a couple of minutes. After incubating the mixture for 30 minutes, ascorbic acid, at the obligatory amount, was added to the mixture and incubated at $60^{\circ} \mathrm{C}$ for 30 minutes. Finally, after completing the copper oxide reduction course, the solution was cleaned with ethanol and centrifuged at $450 \mathrm{~g}$ to collect the copper colloid. Changed values of ascorbic acid were used to control the size of CuO-NPs. Zeta Sizer maneuver (Malvern zeta sizer nano-25) and Transmission electron microscope (TEM) (MIRA3- TESCAN) were used for evaluation of the size and morphology of CuO-NPs.

\section{Antimicrobial susceptibility tests of $\mathrm{CuO}-\mathrm{NPS}$ Disk diffusion test}

To implement this test, clinical strains and standard strains of the bacteria of $A$. baumannii and S. epidermidis were cultured in the BHI medium and incubated at $37^{\circ} \mathrm{C}$ for 24 hours. Then, the turbidity of the cultured bacterial strains was controlled by using the 0.5 McFarland standard method (Bahar Afshan-Iran) and using a spectrophotometer (Jenway 6305) at a $600 \mathrm{~nm}$ wavelength to achieve $1.5 \times 10^{8} \mathrm{CFU} / \mathrm{ml}$ from each bacterial strain. 
Thereafter, bacteria strain was cultured distinctly using a germ-free swab on Mueller Hinton agar. After that, $20 \mu \mathrm{l}$ of $1 \mathrm{mg} / \mathrm{ml}$ synthesized nanoparticles ( 30 or $60 \mathrm{~nm}$ ) were loaded on the $6 \mathrm{~mm}$ sterile standard disks (Padtan-Iran) in $8 \mathrm{~cm}$ plates. Unloaded disks (Padtan-Iran) were also used as control. Finally, they were incubated for 24 hours at 37 ${ }^{\circ} \mathrm{C}$, and then the diameter of the inhibition zone designed around the disks loaded with the nanoparticles was measured using a caliper and informed as to the mm unit.

\section{Agar well diffusion test}

Briefly, 0.5 McFarland standard was obtained from bacteria. After that, the bacterial strains were cultured on a regular medium, and a well was generated by using a disinfected punch inside the plate. Next, $50 \mu \mathrm{l}$ of $1 \mathrm{mg} / \mathrm{ml}$ of $\mathrm{CuO}-\mathrm{NPs}$ was injected in each well on separate plates, while the wells containing Dimethyl Sulfoxide (DMSO) (Merck-Germany) were organized as a control. Plates were incubated for 24 hours at $37^{\circ} \mathrm{C}$. Then, the diameter of the inhibition region formed around the wells containing the nanoparticle was measured, expending a caliper and informed in mm unit.

Minimal inhibitory concentration (MIC) and minimum bactericidal concentration (MBC) tests

The protocol presented by Raeisi and colleagues (Raeisi, Tajik et al. 2016) was used to analyze the minimal inhibitory concentration (MIC) and minimum bactericidal concentration (MBC). Briefly, different concentrations of CuO-NPs were prepared by using the Tryptic Soy Broth medium. At the same time, $0.5 \mathrm{McF}$ arland standard was obtained from bacteria. After that, dilutions ranging from 2 to 7 times more than the dilution of the leading solutions of CuO-NPs were equipped in tubes comprising BHI (78 to $10000 \mu \mathrm{g} / \mathrm{ml}$ ) to determine MIC, and MBC. First, 20 $\mu \mathrm{l}$ of prepared concentrations of CuO-NPs, $160 \mu \mathrm{l} \mathrm{BHI}$, and $20 \mu \mathrm{l}$ of bacterial inoculation were added for each bacterial strain distinctly in micro-plate wells. For positive control, $200 \mu \mathrm{l}$ of BHI medium and nanoparticle, and for the negative control, $180 \mu \mathrm{l}$ of BHI medium along with $20 \mu \mathrm{l}$ of bacterial inoculation were added to the wells. The micro-plates were shaken for 1 minute on the plate thermo-shaker device and incubated at $37^{\circ} \mathrm{C}$ for 37 hours. After a period of time, the wells were observed in terms of creation- or non-creation of turbidity, and the first translucent well was measured to be MIC, and the second one was measured to be MBC well.

\section{Investigating the bacterial survival/growth kinetics}

In summary, $8 \mathrm{ml}$ of BHI broth medium was initially added in four tubes, and $1 \mathrm{ml}$ of 18 -hour culture on the bacterial strain was inoculated into the BHI medium. Besides, $1 \mathrm{ml}$ of $\mathrm{CuO}-\mathrm{NPs}$ with dilutions of $0.1,0.01$, and $0.001 \mathrm{mg} / \mathrm{ml}$ was initially transferred into three tubes individually. Physiology serum had been added to the fourth tube as the control. Subsequently, media have been incubated at $37^{\circ} \mathrm{C}$, and each of the considered concentrations was initially diluted at intervals of 0.15 , 30,45 , and $60 \mathrm{~min}$ and cultured on plates including the BHI agar channel. Subsequently, the cultured plates had been incubated at $37^{\circ} \mathrm{C}$ for 24 hours. After incubation,
Effect of Copper Oxide Nanoparticles on Cancer and Bacteria

the amount of survived bacteria was calculated using the colony counter, plus the bacterium survival/growth moment curve seemed to be plotted. This evaluation was executed in three replications for each bacterial strain independently, and standard deviations of principles were calculated ( $p$ price $<0.05$ ).

\section{Anti-cancer potential tests of $\mathrm{CuO}-\mathrm{NPS}$ \\ Cell culture and treatment}

Mouse-breast cancer cell line, namely 4T1, was purchased from the National Cell Bank of Iran (NCBI, Tehran, Iran) and was cultured in a $25-\mathrm{cm}^{2}$ flask at the density of $5 \times 10^{4}$ cells $/ \mathrm{cm}^{2}$ in a regular medium (RPMI 1960 supplement with $10 \%$ FBS, $100 \mathrm{IU} / \mathrm{ml}$ streptomycin, and $1 \%$ glutamine plus $100 \mathrm{IU} / \mathrm{ml}$ penicillin) incubated in $5 \% \mathrm{CO}_{2}$ at $37^{\circ} \mathrm{C}$. After reaching confluency of $80 \%$, cells were trypsinized, harvested, and seeded in six or 96well plats and incubated for $24 \mathrm{hrs}$. Afterward, cells were treated with $\mathrm{CuONPs}(30$ and $60 \mathrm{~nm})$ at the concentrations of 0 (as a control), 5, 10, and $20 \mu \mathrm{g} / \mathrm{ml}$ for $24 \mathrm{hrs}$.

\section{Measurement of cell viability/proliferation by MTT assay}

MTT assay was performed to evaluated cell viability/ proliferation of $4 \mathrm{~T} 1$ cells after exposure to $\mathrm{CuO}$ NPs. In 96-well plates, $4 \mathrm{~T} 1$ cancer cells $\left(5 \times 10^{4}\right.$ cells/well $)$ were seeded in $200 \mu \mathrm{l}$ regular medium overnight. After that, they were treated with different concentrations (described above) for $24 \mathrm{hrs}$; the procedure previously described by Rahmani-Kukia et al. (Abbasi, Kukia et al. 2018, RahmaniKukia, Abbasi et al. 2020) was performed. Briefly, $20 \mu 1$ of MTT solution ( $5 \mathrm{mg} / \mathrm{ml}$ in PBS) was added to each well and incubated for four hours at a cell culture incubator. The supernatant was discarded, and $100 \mu$ l of DMSO was added to each well. In the following, optical density (OD) was measured by an ELISA microplate reader at $540 \mathrm{~nm}$. Finally, the difference in viability/proliferation between control and the treated cells was evaluated with the following equation:

Viability rate (\%): (OD of the treated cells/ OD of the control cells) $\times 100$.

\section{Measurement of cell apoptosis using acridine orange(AO) and propidium iodide(PI)}

Apoptosis was determined by AO and PI. Cancer cells were seeded in six-well plates $\left(1 \times 10^{6}\right.$ cells/well $)$ and were allowed to carpet the wells for $24 \mathrm{~h}$. After being treated with different concentrations (as described above) for $24 \mathrm{hrs}$, the supernatant was removed, and the cells were washed twice with PBS. After staining with $10 \mu$ l of AO (AO, Sigma Aldrich $10 \mu \mathrm{g} / \mathrm{ml})$, cells were incubated for 15 minutes at $25^{\circ} \mathrm{C}$ in dark condition. $10 \mu \mathrm{l}$ of PI (PI, Sigma Aldrich $10 \mu \mathrm{g} / \mathrm{ml}$ ) was immediately added before measurement by a fluorescent microscope. Then the percentage of cells exhibiting apoptosis patterns was counted and calculated.

Measurement of cell migration and angiogenesis-related gene expression

Cancer cells were seeded in six-well plates $\left(1 \times 10^{6}\right.$ cells/well) and were allowed to carpet the wells for $24 \mathrm{~h}$. 
After treated with different concentrations (as described above) for $24 \mathrm{hrs}$, total RNA was extracted from cells using an isolation RNA kit (Thermo Fisher Scientific), according to the manufacturer's instructions with an RNA quality of 1.9. Complementary DNA (cDNA) was synthesized using a cDNA Synthesis Kit (Thermo Fisher Scientific), based on the manufacturer's instructions. The expression level of MMP-2 (as cell migration biomarker) and VEGF (as angiogenesis biomarker) were evaluated by Step-one plus Real-time PCR system (Applied Bio-Systems). This process was steed with primers including MMP-2 (F- GGACAAGAACCAGATCACATAC, R-C G T C G C T C C A T A C T T T T A A G G), VEGF (F-GGATCAAACCTCACCAAAGC, R-GCAGGAACATTTACACGTCTG) and an endogenous control geneHPRT(F-CAGGACTGAAAGACTTGCTC, R-AGGTCAGCAAAGAACTTATAGC). According to application, an analysis of fold change expression was determined.

\section{Statistical analysis}

Statistical significance was performed by two-way ANOVA analysis of variance using Graph Pad Prism 7.0 for Windows (Graph Pad Software, Inc., San Diego, CA, USA). ${ }^{*} \mathrm{p}<0.05, * * \mathrm{p}<0.01, * * * \mathrm{p}<0.001$ and $* * * *$ $\mathrm{p}<0.0001$ were considered as significance level for all analyses performed. Data were presented as mean \pm SD in triplicates experiments.

\section{Results}

\section{Size and morphology of $\mathrm{CuO}-\mathrm{NPS}$}

Investigation of the size of synthesized $\mathrm{CuO}-\mathrm{NPs}$ using the Zeta Sizer device and a specified value of ascorbic acid showed that $\mathrm{CuO}-\mathrm{NPs}$ were synthesized with the approximate sizes of 30 and $60 \mathrm{~nm}$ Transmission Electron Microscope (TEM) investigations also proved the 30 and $60 \mathrm{~nm}$ of CuO-NPs (see Figure 2).

\section{Antibiogram Test Results}

The results showed that $S$. epidermidis bacteria were sensitive to Trimethoprim-sulfamethoxazole and Novobiocin while resistant to other antibiogram discs (Figure-3). A. baumannii was only sensitive to the Ampicillin-sulbactam antibiotic disc and was resistant to

Table 1. The Results of Disk Diffusion Test and Well Diffusion Tests in the Treatment of $S$. epidermidis and $A$. baumannii Bacteria (Standard and Clinical Strains) with Two Different Sizes of CuO-NPs (30 and $60 \mathrm{~nm}$ ).

\begin{tabular}{lcccc}
\hline $\begin{array}{l}\text { The type of } \\
\text { bacteria }\end{array}$ & $\begin{array}{c}\text { Size of } \\
\text { Nanoparticle }\end{array}$ & $\begin{array}{c}\text { Disc } \\
(\mathrm{mm})\end{array}$ & $\begin{array}{c}\text { Well Agar } \\
(\mathrm{mm})\end{array}$ & $\begin{array}{c}\text { Negative } \\
\text { Control }\end{array}$ \\
\hline $\begin{array}{l}\text { S. epidermidis } \\
\text { (Standard) }\end{array}$ & $30 \mathrm{~nm}$ & $19 \pm 1.3$ & $28 \pm 1.5$ & 0 \\
$\begin{array}{l}\text { S. epidermidis } \\
\text { (Clinical) }\end{array}$ & $30 \mathrm{~nm}$ & $15 \pm 2$ & $23 \pm 2$ & 0 \\
$\begin{array}{l}\text { A. baumannii } \\
\text { (Standard) }\end{array}$ & $60 \mathrm{~nm}$ & $10 \pm 2$ & $21 \pm 1$ & 0 \\
$\begin{array}{l}\text { A. baumannii } \\
\text { (Clinical) }\end{array}$ & $30 \mathrm{~nm}$ & $13 \pm 1$ & $18 \pm 1.5$ & 0 \\
\hline
\end{tabular}

other antibiotic discs (Figure 3). As a result, the clinical bacteria used in this study had antibiotic resistance.

\section{Results of $\mathrm{CuO}$ NPs antibacterial properties} Well diffusion and Disk diffusion test results

As results are shown in Table 1, the mean diameter of inhibition zone resulting from the treatment of S. epidermidis standard and clinical strains were $19 \pm$ $1.3,15 \pm 1.5 \mathrm{~mm}$ for $30 \mathrm{~nm}$ and $14 \pm 2,10 \pm 2 \mathrm{~mm}$ for $60 \mathrm{~nm} \mathrm{CuO-NPs,}$ respectively, whereas A. baumannii standard and clinical strains had $13 \pm 1$ and $9 \pm 1.5 \mathrm{~mm}$ for $30 \mathrm{~nm}$ and $9 \pm 2.5$ and $5 \pm 2 \mathrm{~mm}$ for $60 \mathrm{~nm} \mathrm{CuO}-\mathrm{NPs}$, respectively. On the other hand, these values in the well diffusion test with $30 \mathrm{~nm}$ and $60 \mathrm{~nm} \mathrm{CuO-NPs} \mathrm{exposed}$ with $S$. epidermidis clinical and standard strains were $28 \pm$ 1.5 and $26 \pm 2 \mathrm{~mm}$ for $30 \mathrm{~nm}$ and $23 \pm 2$ and $21 \pm 1 \mathrm{~mm}$ for $60 \mathrm{~nm}$, respectively. Moreover, for A. baumannii clinical and standard strains were $18 \pm 1.5,11 \pm 2 \mathrm{~mm}$ for $30 \mathrm{~nm}$, and $14 \pm 1.5$ and $9 \pm 1.5 \mathrm{~mm}$ for $60 \mathrm{~nm}$, respectively.

\section{$M I C$ and $M B C$ test results}

In brief, the data obtained in determining the MIC and MBC show that $\mathrm{CuO}-\mathrm{NPs}$ had significant antibacterial effects on the standard strain compared to clinical strain on both $A$. baumannii and $S$. epidermidis bacteria. Furthermore, the smaller size $(30 \mathrm{~nm})$ of the CuO-NPs has more antibacterial properties than the larger size (60 $\mathrm{nm})$. Table-2 shows these differences.

\section{Bacterial survival/growth kinetics test results}

Investigation of $\mathrm{CuO}-\mathrm{NPs}$ exposure in two different sizes of CuO-NPs, 30 and $60 \mathrm{~nm}$, in different times, were done on A. baumannii and S. epidermidis bacteria in standard and clinical strains. In Figure 4, the results showed that $\mathrm{CuO}-\mathrm{NPs}$ significantly reduced the viability and growth of $S$. epidermidis bacteria in both standard and clinical strains in both doses and at different times. Nevertheless, this decrease in viability was more significant at concentrations of $0.1 \mathrm{mg}$ than 0.01 and $0.001 \mathrm{mg}$. Similarly, in Figure 5, the results showed that $\mathrm{CuO}-\mathrm{NPs}$ in the dose and time-dependent manner reduced the growth and viability of $A$. baumannii in standard and clinical strains. It also had higher antibacterial activity than A. baumannii at a concentration of $0.1 \mathrm{mg}$ and 30 $\mathrm{nm}$. Interestingly, clinical strains were more resistant

Table 2. MIC $(\mu \mathrm{g} / \mathrm{ml})$ and MBC $(\mu \mathrm{g} / \mathrm{ml})$ in the Treatment of $S$. epidermidis and A. baumannii Bacteria (Standard and Clinical Strains) with Two Different Sizes of CuO-NPs (30 and $60 \mathrm{~nm}$ ).

\begin{tabular}{lccc}
\hline $\begin{array}{l}\text { The type of } \\
\text { bacteria }\end{array}$ & $\begin{array}{c}\text { Size of } \\
\text { Nanoparticle }\end{array}$ & MIC $(\mathrm{g} / \mathrm{ml})$ & $\mathrm{MBC}(\mathrm{g} / \mathrm{ml})$ \\
\hline $\begin{array}{l}\text { S. epidermidis } \\
\text { (Standard) }\end{array}$ & $30 \mathrm{~nm}$ & 2,500 & $\geq 5,000$ \\
$\begin{array}{l}\text { S. epidermidis } \\
\text { (Clinical) }\end{array}$ & $60 \mathrm{~nm}$ & 5,000 & $\geq 10,000$ \\
A. baumannii & $60 \mathrm{~nm}$ & 5,000 & $\geq 10,000$ \\
(Standard) & $30 \mathrm{~nm}$ & 10,000 & $\geq 10,000$ \\
A. baumannii & $60 \mathrm{~nm}$ & 5,000 & $\geq 10,000$ \\
(Clinical) & $30 \mathrm{~nm}$ & 10,000 & $\geq 10,000$ \\
\hline
\end{tabular}


A
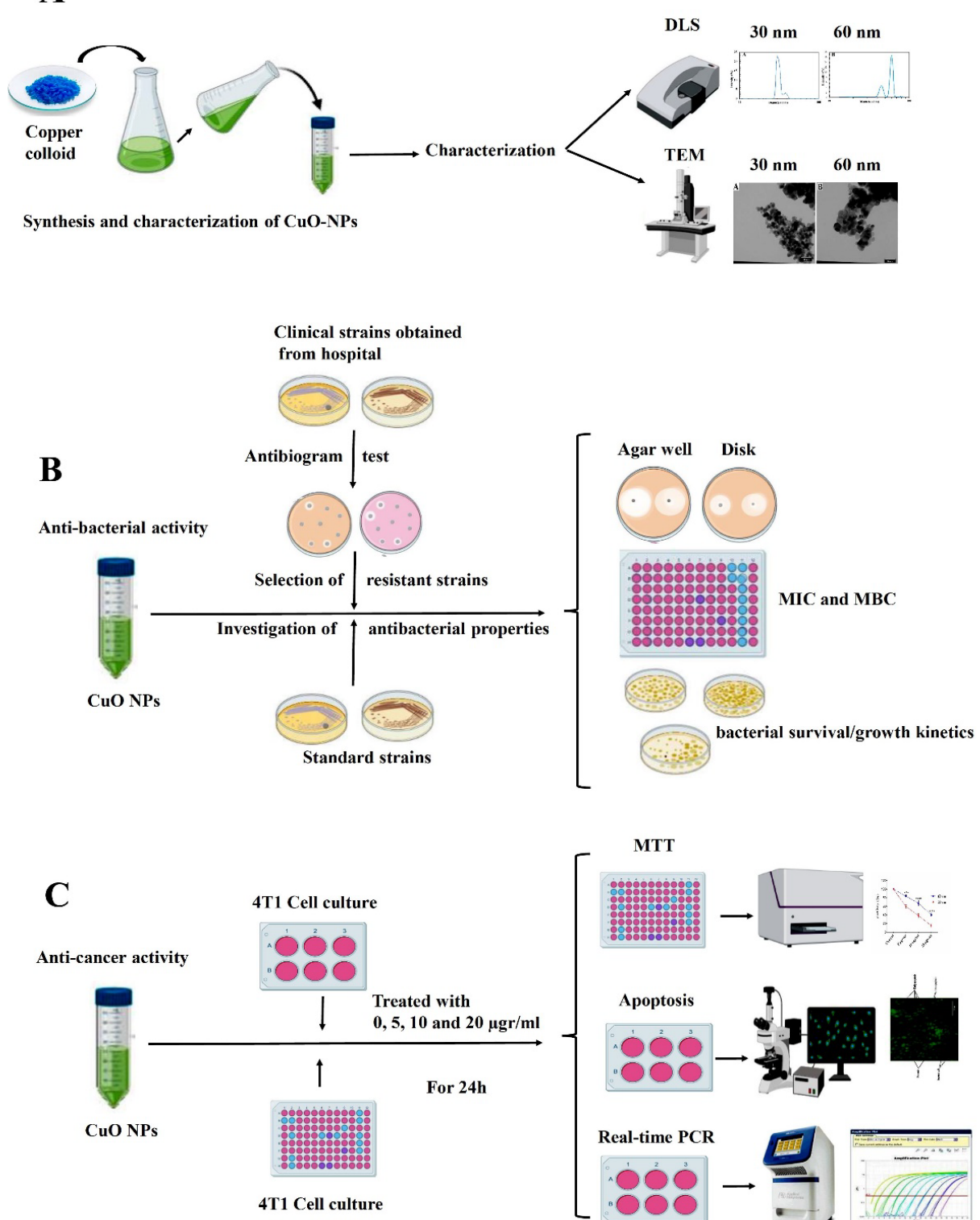

MTT

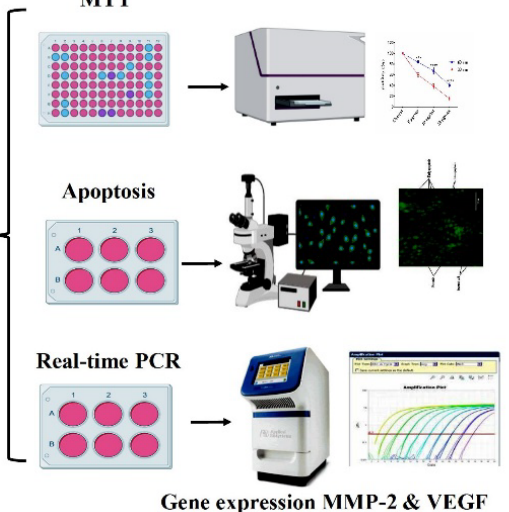

Figure 1. Schematic form of Project Design. A, In the first step, copper oxide nanoparticles are synthesized using the one-step reduction method, then size and morphology characterization of CuO-NPs was performed by DLS and TEM methods. B, In the second step, bacteria resistant to common antibiotics were isolated from the infectious section of the hospital. On the other hand, Standard bacterial strains were prepared. Afterthought antibacterial properties of $\mathrm{CuO}-\mathrm{NPs}$ on standard and clinical strains of the bacteria of A. baumannii and S. epidermidis were investigated by disk, well diffusion testing, MIC, MBC, and bacterial survival/growth kinetics methods. C, In the third step, the anti-cancer activity of $\mathrm{CuO}$ NPs on the 4T1 breast cancer cell line was evaluated by MTT, Apoptosis, and Real-time PCR for gene expression of MMP-2 and VEGF as metastatic and angiogenesis of cancer cell.

than standard strains of both $\mathrm{CuO}-\mathrm{NPs}$, and the $30 \mathrm{~nm}$ $\mathrm{CuO}-\mathrm{NPs}$ were significantly more effective than the 60 $\mathrm{nm}$. On the other hand, it was found that $S$. epidermidis bacteria were more sensitive than A. baumannii to $\mathrm{CuO}-\mathrm{NPs}$ in both standard and clinical strains.

Results of the anti-cancer potential of $\mathrm{CuO}-\mathrm{NPS}$ Size and concentration-dependent of $C u O N P$ s on cancer cell viability/proliferation

The effect size and concentration of $\mathrm{CuO}$ NPs on the viability/proliferation of breast cancer cell line was performed by MTT assay. According to Figure $6 \mathrm{~B}$, increasing the concentration in both sizes has reduced the viability of cancer cells. On the other hand, it has been found that the size of $30 \mathrm{~nm}$ has a more significant effect on all concentrations similar to $60 \mathrm{~nm}$ of $\mathrm{CuO}$ NPs and further reduced the viability/proliferation of breast cancer cells. The half- maximal inhibitory concentration (IC50) indicated at what concentration of $\mathrm{CuO}$ NPs inhibited the growth of cancer cells $(50 \%)$ compare to the untreated cells. The $\mathrm{IC}_{50}$ of $\mathrm{CuO}$ NPs with size 30 $\mathrm{nm}$ were $8.2 \pm 2.4$, and for $\mathrm{CuO}$ NPs with size $60 \mathrm{~nm}$ were $13.3 \pm 1.8$. The $\mathrm{IC}_{50}$ has significantly been increased by decreasing particle size. 

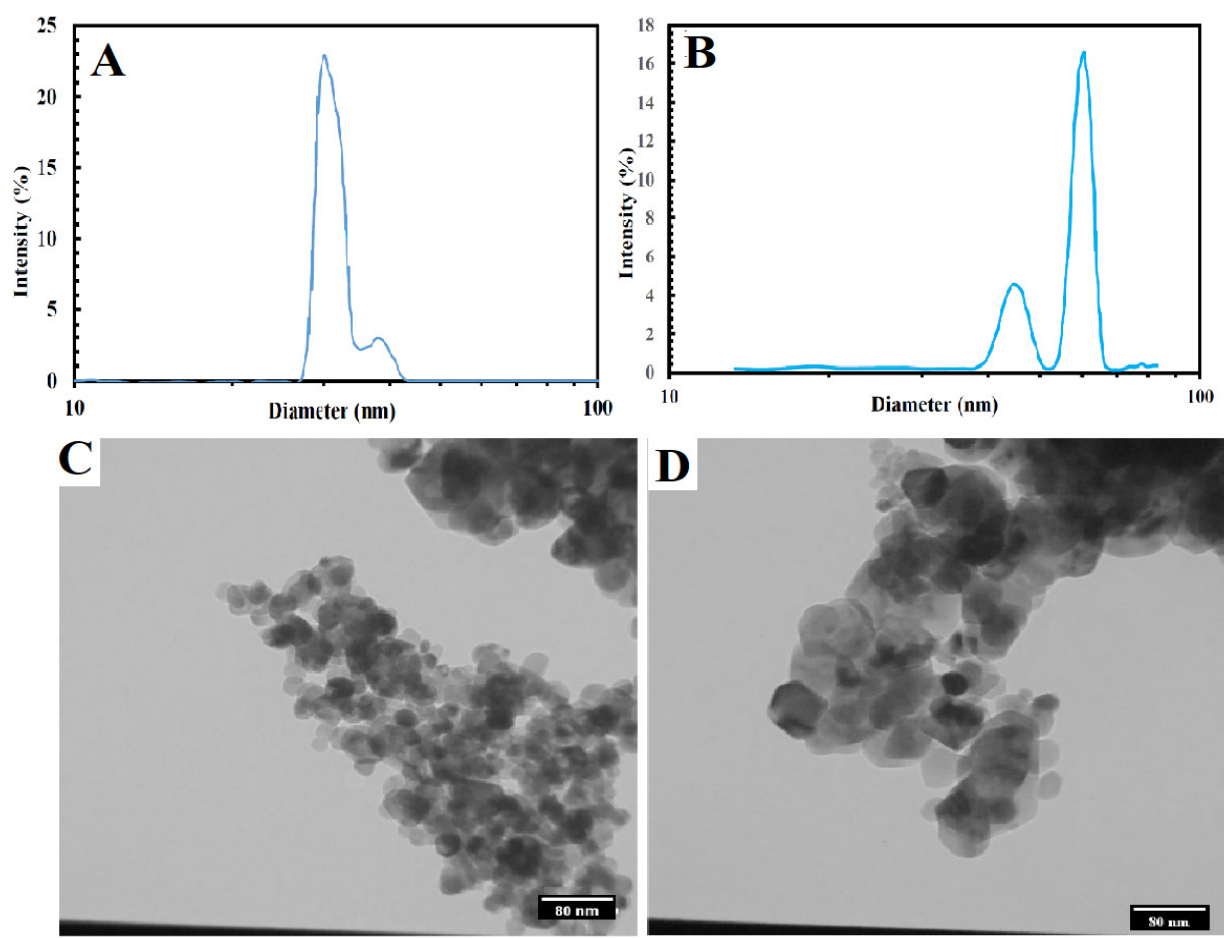

Figure 2. Hydrodynamic Diameter (Determining the Size) of CuO-NPs via DLS and TEM Results of Synthesized CuO-NPs. A, $30 \mathrm{~nm}$ of CuO-NPs. B, $60 \mathrm{~nm}$ of CuO-NPs. C, Morphology of CuO-NPs with $30 \mathrm{~nm}$. D: Morphology of $\mathrm{CuO}-\mathrm{NPs}$ with $60 \mathrm{~nm}$.

Quantification of cell apoptosis by fluorescence microscopic

Fluorescence microscopic study was performed to evaluate whether the cytotoxic effect of CuO NPs was related to the stimulation of apoptosis or to the induction of apoptosis. Under the microscope, normal cells were seen as bright green, while early apoptotic cells demonstrated bright green areas of condensed chromatin in the nucleus and necrotic cells represented a uniform bright red nucleus with non-condensed chromatin (include PI). After microscopic examination, Figure $6 \mathrm{C}$ has shown that the rate of apoptosis in $4 \mathrm{~T} 1$ cancer cells significantly increases in a dose dependent-manner in both CuO NPs concentration. Also, compared with the effect of size of $\mathrm{CuO} \mathrm{NPs}$, it has been found that smaller $\mathrm{CuO}$ NPs aggregation increases apoptosis in 4T1 cancer cells. Figure 6A shown fluorescence inverts microscopic images of $\mathrm{CuO}$ NPs - exposed cells stained by AO/PI.

Evaluate of malignancy after treatment of $4 T 1$ cell line with $\mathrm{CuO} N \mathrm{NP}$

Assessment of malignancy after 4T1 cell line exposed with $\mathrm{CuO}$ NPs was based on two indices, including MMP-2 as tumor metastatic potential representative and VEGF as angiogenesis representative for migratory tendency. In Figure 7 A, B demonstrated that in both $\mathrm{CuO}$ NPs sizes, increasing the concentration reduced the expression of MMP-2 and VEGF genes in breast cancer cells. Comparing the effect of size on the expression of these genes, it was found that smaller nanoparticles inhibit the expression of genes involved in metastasis and angiogenesis in $4 \mathrm{~T} 1$ cancer cells. Finally, it was found that $\mathrm{CuO}$ NPs with size $30 \mathrm{~nm}$ were more effective than $\mathrm{CuO}$ NPs with size $60 \mathrm{~nm}$ in reducing viability/proliferation,

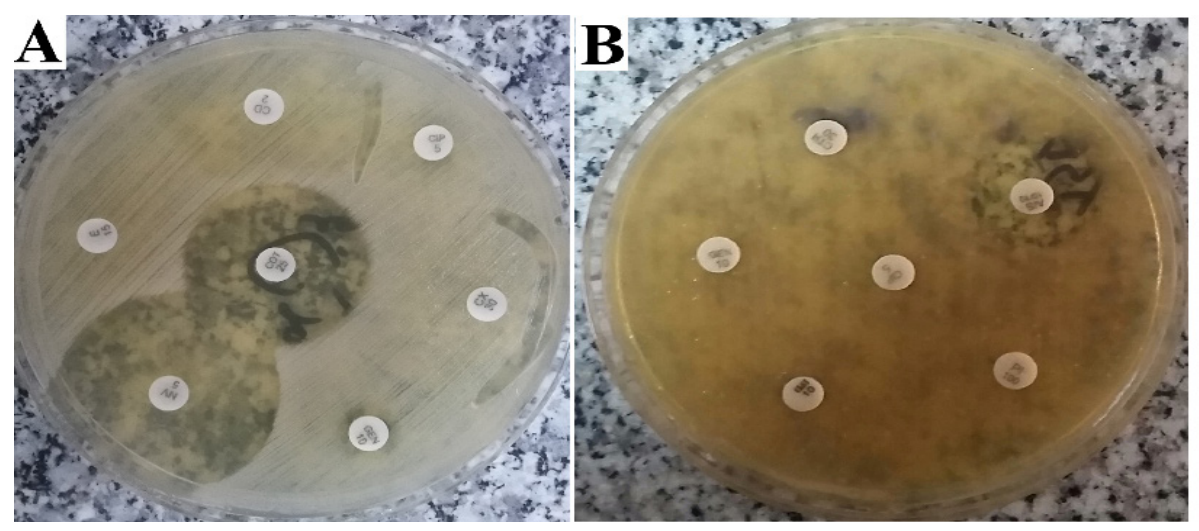

Figure 3. Antibiotic Resistance Clinical Strain of S. epidermidis and A. baumannii Bacteria by Antibiogram Test. A, Antibiotic disks were used for S. Epidermidis bacteria. B, Antibiotic disks were used for A. Baumannii bacteria 
A

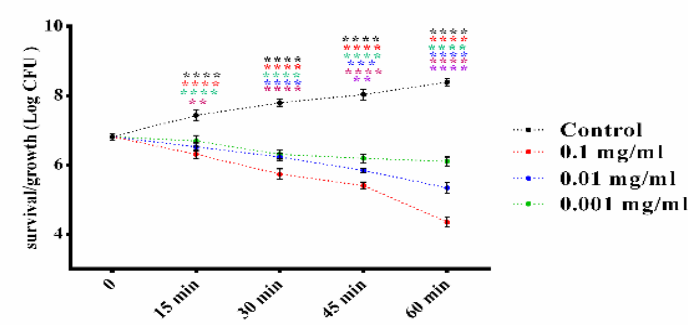

C

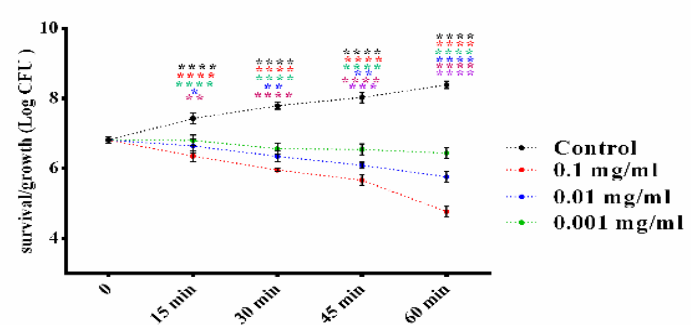

B

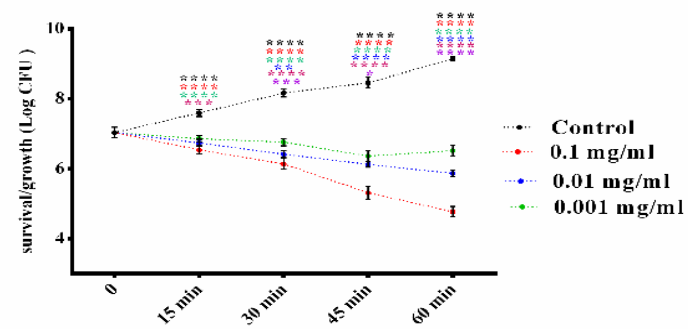

D

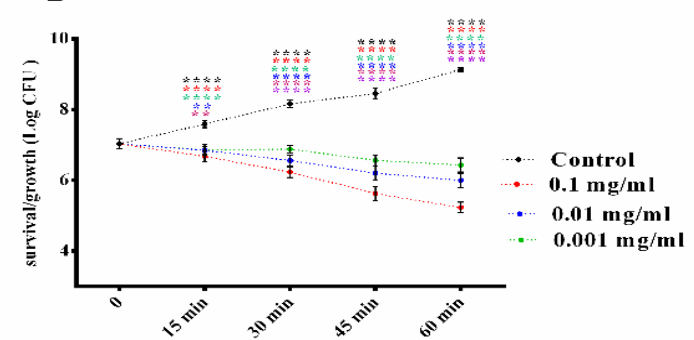

Control vs. $0.1 \mathrm{mg} / \mathrm{m}$

Control vs. $0.01 \mathrm{mg} / \mathrm{ml}$

Control vs. $0.001 \mathrm{mg} / \mathrm{ml}$

$0.1 \mathrm{mg} / \mathrm{ml}$ vs. $0.001 \mathrm{mg} / \mathrm{mi}$

$0.01 \mathrm{mg} / \mathrm{ml} \mathrm{vs.} 0.001 \mathrm{mg} / \mathrm{ml}$

Figure 4. S. epidermidis Standard and Clinical Strains Survival/Growth Curves in the Presence of Different Concentrations $(0.1,0.01,0.001 \mathrm{mg})$ and Different Sizes $(30$ or $60 \mathrm{~nm})$ of CuO NPs $(\mathrm{mg} / \mathrm{mL})$. A, Standard strain treated with $30 \mathrm{~nm}$ size of CuO NP. B, Clinical strain treated with $30 \mathrm{~nm}$ size of CuO NP. C, Standard strain treated with $60 \mathrm{~nm}$ size of CuO NP. D, clinical strain treated with $60 \mathrm{~nm}$ size of CuO NP. Data shown are means \pm SD $(n=3)$ $(* \mathrm{p}<0.05, * * \mathrm{p}<0.01, * * * \mathrm{p}<0.001$ and $* * * * \mathrm{p}<0.0001 \mathrm{vs}$ similar concentrations in different conditions and each index is represented with assigned color in legend

$\mathbf{A}$

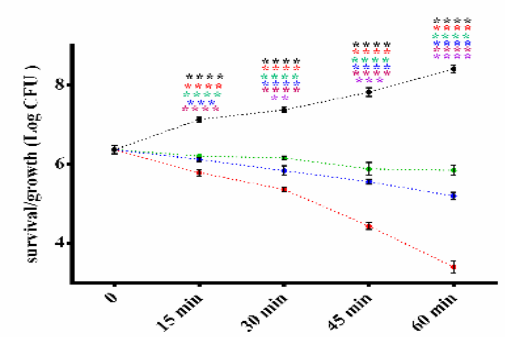

C

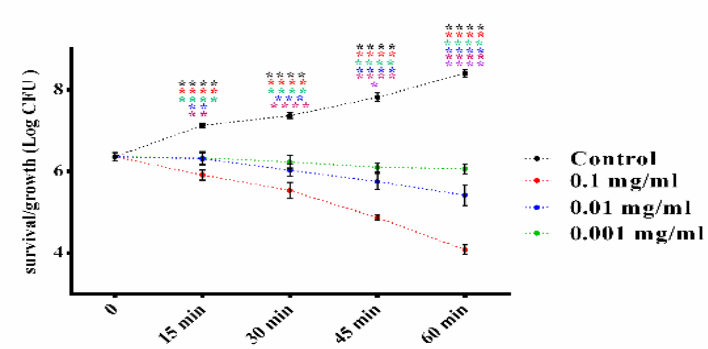

B

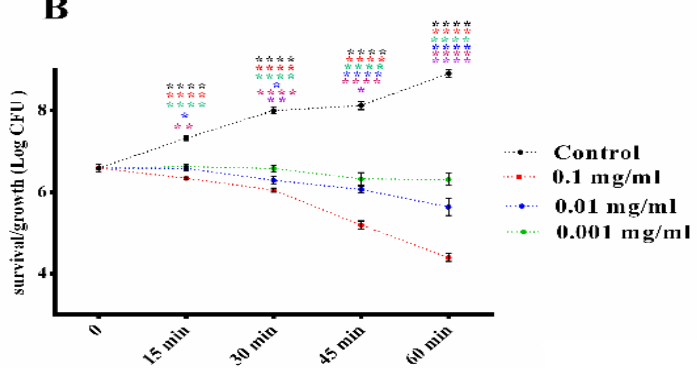

$\mathbf{D}$

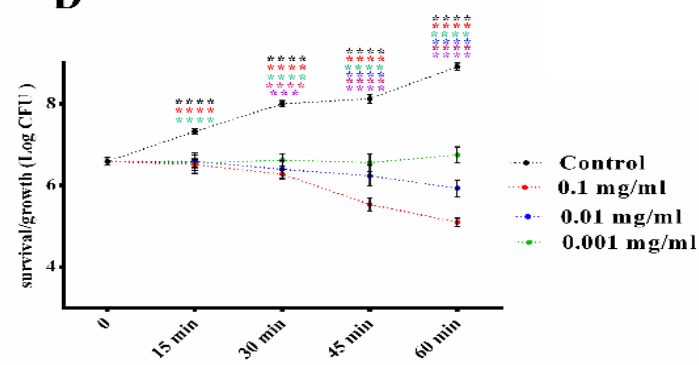

\footnotetext{
Control vs. 0.1 mg/ml

Control vs. $0.001 \mathrm{mg} / \mathrm{ml}$

$0.1 \mathrm{mg} / \mathrm{ml}$ vs. $0.01 \mathrm{mg} / \mathrm{ml}$

$0.1 \mathrm{mg} / \mathrm{ml}$ vs. $0.001 \mathrm{mg} / \mathrm{ml}$

$0.01 \mathrm{mg} / \mathrm{ml}$ vs. $0.001 \mathrm{mg} / \mathrm{ml}$
}

Figure 5. A. baumannii Standard and Clinical Strains Survival/Growth Curves in the Presence of Different Concentrations $(0.1,0.01,0.001 \mathrm{mg})$ and Different Sizes $(30$ or $60 \mathrm{~nm}$ ) of CuO NPs $(\mathrm{mg} / \mathrm{mL})$. A, Standard strain treated with $30 \mathrm{~nm}$ size of CuO NP. B, Clinical strain treated with $30 \mathrm{~nm}$ size of CuO NP. C, Standard strain treated with $60 \mathrm{~nm}$ size of $\mathrm{CuO}$ NP. D, clinical strain treated with $60 \mathrm{~nm}$ size of CuO NP. Data shown are means $\pm \mathrm{SD}(\mathrm{n}=3)$ $(* \mathrm{p}<0.05, * * \mathrm{p}<0.01, * * * \mathrm{p}<0.001$ and $* * * * \mathrm{p}<0.0001$ vs similar concentrations in different conditions and each index is represented with assigned color in legend. 

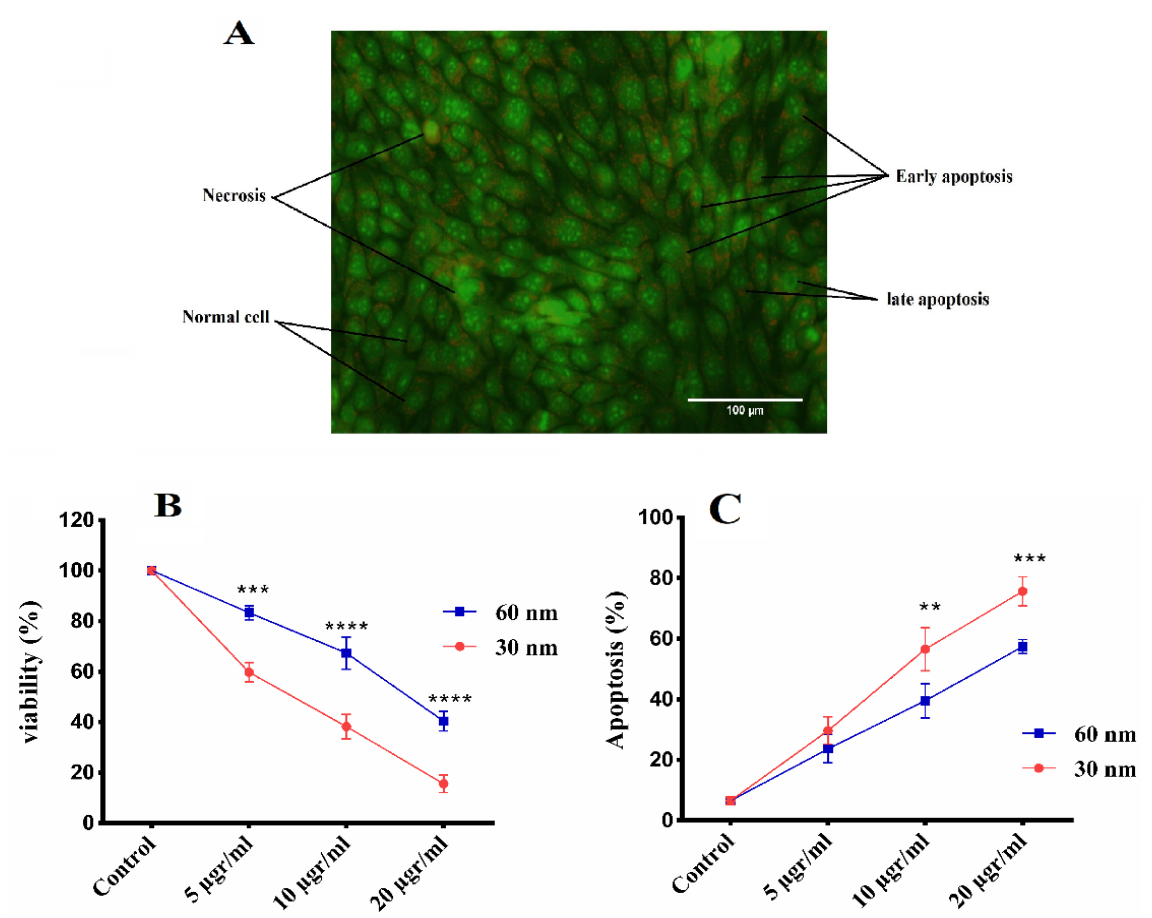

Figure 6. A, apoptosis morphological change of effect different concentration and the different size of CuO NPs on the $4 \mathrm{~T} 1$ breast cancer with AO/ PI staining by fluorescence microscope. B, Cancer cell viability in exposing different concentrations of $\mathrm{CuO}$ NPs in sizes 30 and $60 \mathrm{~nm}$ by MTT assay. C, Determination of apoptosis of breast cancer cells treated with different concentrations of CuO NPs in 30 and $60 \mathrm{~nm}$ sizes. Data shown are means $\pm \operatorname{SD}(n=3)(* p<0.05$, $* * \mathrm{p}<0.01, * * * \mathrm{p}<0.001$ and $* * * * \mathrm{p}<0.0001$ vs similar concentrations in different size).

A

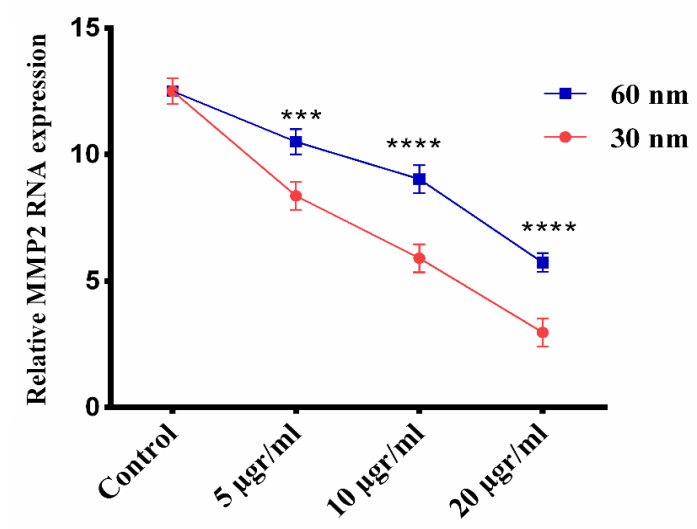

B

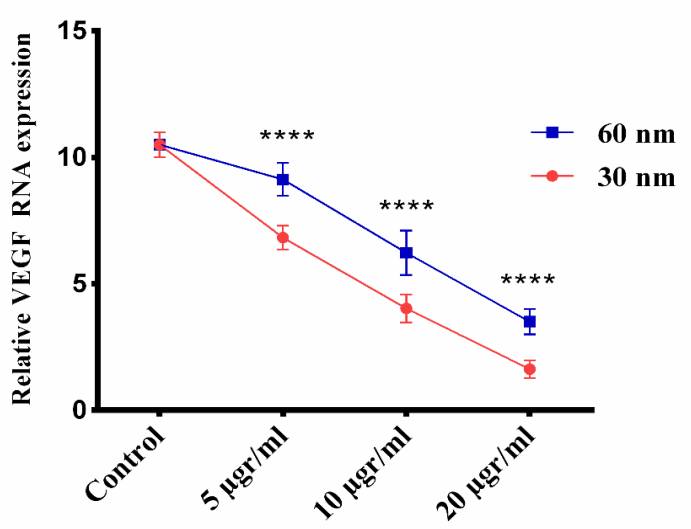

Figure 7. The mRNA Expression Levels of MMP-2 (A) and VEGF (B) in Breast Cancer Cell Treatment with Different Concentrations of $\mathrm{CuO}$ NPs in Sizes 30 and $60 \mathrm{~nm}$. HPRT was used for an endogenous control. Data shown are means $\pm \mathrm{SD}(\mathrm{n}=3)(* \mathrm{p}<0.05, * * \mathrm{p}<0.01, * * * \mathrm{p}<0.001$ and $* * * * \mathrm{p}<0.0001$ vs similar concentrations in different size $)$.

increasing apoptosis, and inhibiting the expression of genes involved in metastasis and angiogenesis in the 4T1 cancer cell line.

\section{Discussion}

Despite promising successes in developing new drugs and pharmaceutical biotechnology, infectious diseases and cancer are still the principal causes of mortality and morbidity worldwide. Therefore, finding effective ways to deal with these pathogens and cancers is critical. Metal nanoparticles are one of the new strategies to combat bacteria and cancers. In the present study, investigation on the biological effects of $\mathrm{CuO}-\mathrm{NPs}$ on bacteria strains, isolated from hospitals, causing nosocomial infections and impacting on cancers, by the antibiogram test, revealed that $S$. epidermidis and A. baumannii is resistant to a wide range of antibiotics. Additionally, we have selected breast cancer (4T1) as a growing disease and resistance to available drugs.

In our study, one-step oxidation of two CuO-NPs with sizes of 30 and $60 \mathrm{~nm}$ was made and then evaluated on the antibacterial activities of $S$. epidermidis and A. baumannii as an example of gram-positive and negative bacteria 
responsible for NIs in standard and clinical strains and breast cancer.

Our results showed that the synthesized nanoparticles were of one size and morphology. Also, in the study of antibacterial effects of disk and well test, it was found that $30 \mathrm{~nm}$ nanoparticles had more growth areas than $60 \mathrm{~nm}$ nanoparticles with halo diameter. Interestingly, clinical strains illustrated more excellent resistance than standard strains. Based on the results, it could be concluded that the isolates, which are commonplace in the hospital, are developing to be more resistant to antibiotics than the standard strains. It is a warning for the outcome of antibacterial therapeutic strategies. The results also demonstrated that the smaller nanoparticle size had more effects on the resistant strains than the larger nanoparticle size. It has been reported that nanoparticles have some side effects on human cells; hence, using a lower concentration of nanoparticles with more effectiveness is the main goal in antibacterial therapeutic strategies.

On the other hand, our results demonstrated that similar to antibacterial results, in cytotoxicity tests, apoptosis, and expression of genes responsible for cancer cell metastasis and angiogenesis, in both nanoparticles (30 and $60 \mathrm{~nm}$ ) with increased concentration led to decreased survival, expression of MMP-2 and VEGF genes and also increased apoptosis in 4T1 cancer cells. Interestingly, $30 \mathrm{~nm} \mathrm{CuO-NPs}$ at all concentrations compared to 60 $\mathrm{nm} \mathrm{CuO}-\mathrm{NPs}$ have shown a double effect (two folded practical) on anti-cancer and antibacterial properties. Therefore, it appears that lower doses of CuO-NPs in $30 \mathrm{~nm}$ can be effective, whereas the $60 \mathrm{~nm}$ nanoparticle are beneficial in higher doses. Our results are consistent with those obtained by other researchers, whereas using silver nanoparticles with the size between 20 and $30 \mathrm{~nm}$ were associated with an increased inhibitory growth zone on Escherichia coli and S. aureus (Dhand et al., 2016). The beneficial antibacterial effects of gold nanoparticles on pathogenic bacteria have also been reported (Rajan et al., 2015). It has also been shown that $30 \mathrm{~nm} \mathrm{CuO-NPs}$ are more effective than $60 \mathrm{~nm}$ on glioblastoma cancer cells, but there was no significant change (Kukia et al., 2018). These antibacterial and anti-cancer effects of 30 $\mathrm{nm}$ in comparison to $60 \mathrm{~nm}$ nanoparticles (at smaller sizes compared to larger sizes) could be associated with unique physicochemical properties such as higher surface-tovolume ratios, altered electrical, magnetic, and optical properties and higher reactivity, and greater nanoparticle penetration power (Zhang et al., 2010). Besides, smaller nanoparticles increase the antibacterial and anti-cancer activity of $30 \mathrm{~nm}$ by producing cellular ROS, including hydroxyl radical, superoxide anion, and superoxide anion hydrogen peroxide (Belwal et al., 2018).

Interestingly, in our study, clinical bacterium strains were more resistant than standard strains in both nanoparticle sizes. This is because clinical strains were more exposed to environmental factors than the standard strains and increased pumps on their surface. As well as adaptation to more demanding, conditions resulting in increased resistance to antibiotics and even nanoparticles. On the other hand, it has been shown that the effects of metal nanoparticles on different cancer cell lines differ,

\section{Effect of Copper Oxide Nanoparticles on Cancer and Bacteria}

which emphasizes the difference in the resistance of cancer cell lines to these nanoparticles.

Collectively, it appears that the $30 \mathrm{~nm} \mathrm{CuO}-\mathrm{NPs}$ nanoparticle can be considered a potential antibacterial agent, especially in the case of resistance to routine antibiotics. Moreover, it can be used to treat metastatic cancers such as breast cancer. However, since nanoparticles can be associated with some complications, it needs to be initially explored in animal models to evaluate possible in vivo side effects. Additionally, this study proposes that 30 $\mathrm{nm} \mathrm{CuO-NPs}$ could be used to combat metastatic cancer cells, and vehicle disinfectants in hospitals to prevent the growth of resistant bacteria and may include other dangerous biological agents such as viruses (COVID-19) and fungi.

In conclusion, this study suggests that nano-sized nanoparticles (30 or $60 \mathrm{~nm}$ ) could be synthesized for stability and introduced as an intrinsic and potent antimicrobial and anti-cancer agent. In this study, experiments showed that the $30 \mathrm{~nm}$ of CuO-NP had more antibacterial effects against $S$. epidermidis and $A$. baumannii in clinical and standard strains than $60 \mathrm{~nm}$ also and anti-cancer effects against breast cancer, possibly due to the increase in size-to-volume ratio and some other physical and chemical properties and even more, is the ability to penetrate the bacterium and cancer cells. Therefore, it can be concluded that $\mathrm{CuO}-\mathrm{NPs}$ made in a smaller size could be considered an antibacterial and anti-cancer material used in pharmaceutical biotechnology.

\section{Author Contribution Statement}

Study concept and design: Ardeshir Abbasi, and Khoayar Ghorban. Analysis and interpretation of data: Ardeshir Abbasi. Drafting of the manuscript: Ardeshir Abbasi, Khodayar Ghorban, Farshad Nojoomi and Maryam Dadmanesh. Critical revision of the manuscript for important intellectual content: Khodayar Ghorban, Farshad Nojoomi, and Maryam Dadmanesh.

\section{Acknowledgments}

Funding/Support: This work was supported by the Aja University of Medical Sciences.

\section{Conflict of Interests}

The authors declare no conflict of interest.

\section{References}

Abbasi A, Kukia NR, Froushani SMA, Hashemi SM (2018). Nicotine and caffeine alter the effects of the LPS-primed mesenchymal stem cells on the co-cultured neutrophils. Life Sci, 199, 41-7.

Abbasi A, N Pakravan, ZM Hassan (2020). Hyaluronic acid improves hydrogen peroxide modulatory effects on calcium channel and sodium-potassium pump in 4T1 breast cancer cell line.Oxidative Med Cell Longevity, 2020.

Abbasi A, N Pakravan, ZM Hassan (2021). Hyaluronic acid optimises therapeutic effects of hydrogen peroxide-induced oxidative stress on breast cancer. J Cell Physiol, 236, 1494-1514.

Asian Pacific Journal of Cancer Prevention, Vol 22 
Albanese A, PSTang, WC Chan (2012). The effect of nanoparticle size, shape, and surface chemistry on biological systems. Ann Rev Biomed Engin, 14, 1-16.

Ali K, Q Saquib, B Ahmed, et al (2020). Bio-functionalized CuO nanoparticles induced apoptotic activities in human breast carcinoma cells and toxicity against Aspergillus flavus: An In vitro approach. Proc Biochem, 2020.

Amaro F, M Gómez-Mendoza, A Descalzo, L Rivas, G Orellana (2019). Self-sterilizing photoactivated catheters to prevent nosocomial infections. 17th International Photodynamic Association World Congress, International Society for Optics and Photonics.

Atik TK, B Atik, O Kilinç, et al (2018). Epidemiological evaluation of an Acinetobacter baumannii outbreak observed at an intensive care unit. Saudi Med J, 39, 767.

Babaei S, F Bajelani, O Mansourizaveleh, A Abbasi, F Oubari (2017). A study of the bactericidal effect of copper oxide nanoparticles on Shigella sonnei and Salmonella typhimurium. J Babol Univ Med Sci, 19, 76-81.

Baqer AA, K A Matori, NM Al-Hada,et al (2018). Copper oxide nanoparticles synthesized by a heat treatment approach with structural, morphological and optical characteristics. J Mat Sci Mat Electronics, 29, 1025-33.

Belwal T, HP Devkota, HA Hassan, et al (2018). Phytopharmacology of Acerola (Malpighia spp.) and its potential as functional food. Trend Food Sci Technol, 74, 99-106.

Da F, H-S Joo, G Y Cheung, et al (2017). Phenol-soluble modulin toxins of Staphylococcus haemolyticus. Front Cell Infect Microbiol, 7, 206.

Dhand V, L Soumya S, Bharadwaj S, et al (2016). Green synthesis of silver nanoparticles using Coffea arabica seed extract and its antibacterial activity. Mat Sci Engin, 58, 36-43.

Dodoo-Arhin D, M Leoni, P Scardi (2012). Microemulsion synthesis of copper oxide nanorod-like structures. $\mathrm{Mol}$ Crystals Liquid Crystals, 555, 17-31.

Dörner L, C Cancellieri, B Rheingans, et al (2019). Cost-effective sol-gel synthesis of porous $\mathrm{CuO}$ nanoparticle aggregates with tunable specific surface area. Sci Rep, 9, 1-13.

Fernández-Arias M, M Boutinguiza J, Del V, et al (2020). Fabrication and deposition of copper and copper oxide nanoparticles by laser ablation in open air. Nanomaterials, 10, 300.

Grandesso S, B Sapino, G Amici, et al (2014). Are E-test and Vitek2 good choices for tigecycline susceptibility testing when comparing broth microdilution for MDR and XDR Acinetobacter baumannii. New Microbiol, 37, 503-8.

Han T, Z Song, J He, S Li (2010). Influence of ascorbic acid on the stabilization of the copper suspension colloids. Optoel Adv Mat Rapid Commun, 4, 180.

Ilinskaya AN, A Shah, AE Enciso, et al (2019). Nanoparticle physicochemical properties determine the activation of intracellular complement. Nanomed Nanotechnol Biol Med, 17, 266-75.

Kajihara T, K Yahara J, Stelling SR, et al (2020). Comparison of de-duplication methods used by WHO Global Antimicrobial Resistance Surveillance System (GLASS) and Japan Nosocomial Infections Surveillance (JANIS) in the surveillance of antimicrobial resistance." bioRxiv.

Katwal R, H Kaur, G Sharma, et al (2015). Electrochemical synthesized copper oxide nanoparticles for enhanced photocatalytic and antimicrobial activity. J Industrial Engin Chem, 31, 173-84.

Kukia NR, A Abbasi, SMA Froushani (2018). Copper oxide nanoparticles stimulate cytotoxicity and apoptosis in glial cancer cell line. Dhaka Univ J Pharm Sci, 17, 105-11.

Kukia NR, Y Rasmi, A Abbasi, et al (2018). Bio-effects of TiO2 nanoparticles on human colorectal cancer and umbilical vein endothelial cell lines. Asian Pac J Cancer Prev, 19, 2821.

Maddila S, S Gorle, SB Jonnalagadda (2020). Drug screening of rhodanine derivatives for antibacterial activity. Exp Opinion Drug Discov, 15, 203-29.

Mayekar J, V Dhar, S Radha (2014). Synthesis of copper oxide nanoparticles using simple chemical route. Int J Sci Engin Res, 5, 928-30.

Motbainor H, F Bereded, W Mulu (2020). Multi-drug resistance of blood stream, urinary tract and surgical site nosocomial infections of Acinetobacter baumannii and Pseudomonas aeruginosa among patients hospitalized at Felegehiwot referral hospital, Northwest Ethiopia: a cross-sectional study. BMC Infect Dis, 20, 92.

Raeisi M, H Tajik, SMR Rohani, et al (2016). Inhibitory effect of Zataria multiflora Boiss. essential oil, alone and in combination with monolaurin, on Listeria monocytogenes. Veterinary Research Forum, Faculty of Veterinary Medicine, Urmia University, Urmia, Iran.

Rahmani-Kukia N, A Abbasi, SMA Froushani, S Shahgaldi, P Mokarram (2020). The effects of 17 Beta-Estradiol primed mesenchymal stem cells on the biology of co-cultured neutrophil. Int Immunopharmacol, 84, 106602.

Rajan A, V Vilas, D Philip (2015). Studies on catalytic, antioxidant, antibacterial and anticancer activities of biogenic gold nanoparticles. J Mol Liquids, 212, 331-9.

Shahsavani E, N Feizi, KA DEHNO (2016). Copper oxide nanoparticles prepared by solid state thermal decomposition: synthesis and characterization.

Silva N, S Ramírez, I Díaz, A Garcia, N Hassan (2019). Easy, quick, and reproducible sonochemical synthesis of $\mathrm{CuO}$ nanoparticles. Materials, 12, 804.

Yang G, J Xie, F Hong, Z Cao, X Yang (2012). Antimicrobial activity of silver nanoparticle impregnated bacterial cellulose membrane: effect of fermentation carbon sources of bacterial cellulose. Carbohydrate Polymers, 87, 839-45.

Zhang L, Pornpattananangkul D, Hu C-M, Huang C-M (2010). Development of nanoparticles for antimicrobial drug delivery. Curr Med Chem, 17, 585-94.

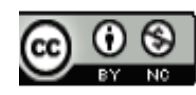

This work is licensed under a Creative Commons AttributionNon Commercial 4.0 International License. 